\title{
Keratocystic odontogenic tumor in the maxillary sinus: A case report
}

\author{
Mohammed H. Al-Bodbaij*, Amjad Al-Ateyah, Rajan Chopra, Nadia Al-Marzooq and Ghada Al-Qassab \\ Oral and Maxillofacial Department, King Fahad Hospital- Hofuf, Hofuf, P.O. Box 5545, KSA
}

\begin{abstract}
This paper describes a case of unilocular keratocystic odontogenic tumor in the left maxillary sinus of a 22 years old Saudi female patient along with the relevant literature review. The maxillary lesion was not associated with any impacted tooth; and it destroyed the posterior wall of the maxillary sinus. The lesion was enucleated and curettage of the sinus floor was done by a rotary instrument. The patient was followed up for about 15 months without any evidence of recurrence. Clinical consideration of a keratocystic odontogenic tumor in the differential diagnoses of the maxillary sinus lesions can affect the modality of treatment being used; and is associated with the possibility of lesion recurrence.
\end{abstract}

\section{Introduction}

Keratocystic odontogenic tumors (KCOT) has been defined by the World Health Organization as a benign intraosseous neoplasm of odontogenic origin with characteristic lining of the parakeratinized squamous epithelium [1]. KCOTs are found in the mandible, especially the posterior portion of the body, approximately twice as much as in the maxilla. Buccal expansion is noted in approximately $30 \%$ of maxillary and $50 \%$ of mandibular lesions [2]. In maxillary canine region KCOT may mimic other lesions such as the inflammatory ones [3].

The origins of KCOT have been suggested as either primordial, including dental lamina rests or the basal cells of the oral epithelium, or dentigerous-like reduced enamel epithelium of the dental follicle [3].

There are two methods of treatment, conservative and aggressive. In the conservative method, simple enucleation with or without curettage and marsupialization is suggested. Aggressive methods include peripheral ostectomy, chemical curettage with Carnoy's solution, and resection [4]. However more specific terminologies describing the treatment modalities in which to be considered as an aggressive or conservative since a surgeon aggressive approach is another's conservative [5].

Reported recurrence rates for KCOT cover a wide range, from 5\% to approximately $70 \%[3]$.

Radiographically, KCOT presents predominantly as a unilocular radiolucency with well-developed sclerotic borders. They may also present as a multilocular radiolucency [6-8]

\section{Case report}

A 22 years old Saudi female presented to our department of Oral and Maxillofacial Surgery at King Fahad Hospital - Hofuf, KSA complaining of pain of left side of the face and recurrent oral discharge of few months duration.

The previous medical history was unremarkable and the extra-oral examination did not show any deformity or alteration.
Intra-oral examination revealed tenderness of left lateral wall of the maxillary sinus without mucosal changes, impacted lower third molars and congenitally missing upper third molars (Figure 1).

Water's view, panoramic and computed tomography (C.T) (Figures 2 and 3) showed a discrete well defined lytic lesion surrounded by a thick radiopaque wall without involving impacted tooth with destruction of poster wall of left maxillary sinus on 3- Dimensional C.T. (Figure 4).

Under general anesthesia, the lesion was enucleated with curettage of the floor of the sinus where the lesion was implanted using rotary

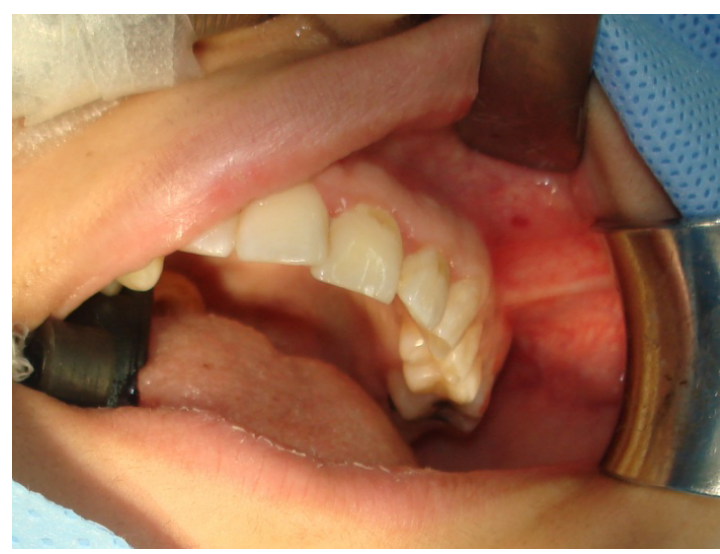

Figure 1. Intra-oral photograph showing normal oral mucosa.

Correspondence to: Mohammed Al-Bodbaij, Oral and Maxillofacial Department, King Fahad Hospital- Hofuf, Hofuf, P.O. Box 5545, KSA, Tel: +96635750000; Ext. 1669; Mobile: +966566470580; Zip No. Hofuf 31982; E-mail: bodbaij@hotmail.com

Key words: enucleation, curettage, impacted, keratocystic odontogenic tumor and maxillary sinus

Received: November 12, 2016; Accepted: December 14, 2016; Published: December 17, 2016 


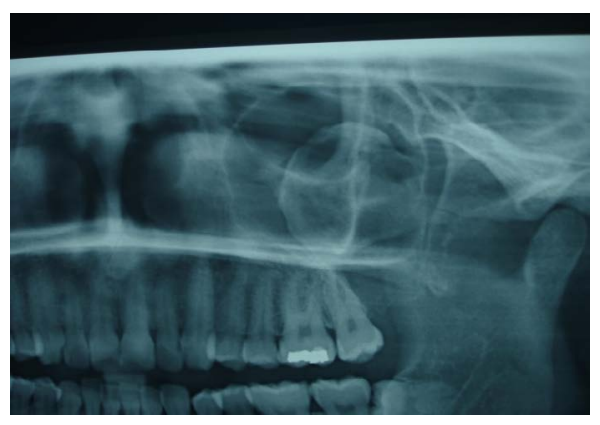

Figure 2. OPG showing a mass into the left maxillary sinus.

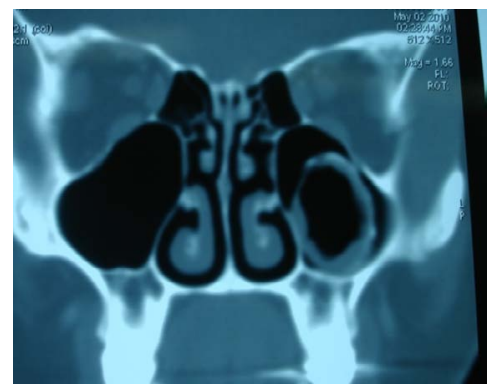

Figure 3. Coronal C.T. Scan showing radiolucent mass with sclerotic thick walls in the left maxillary sinus.

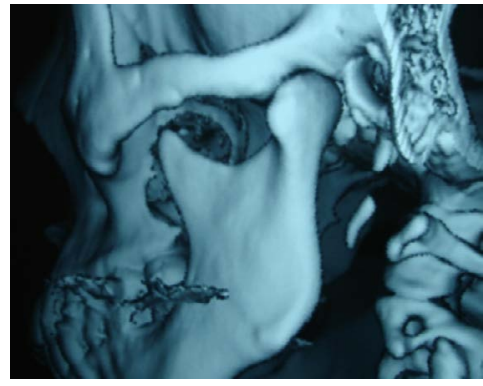

Figure 4. 3- D C.T. Scan shows resorption of posterior wall of left maxillary sinus.

instrument through Caldwell Luc approach (Figures 5 and 6).

The enculated lesion was sent to the laboratory for histological examination which gave the result of parakeratotic Keratocystic odontogenic tumor (Figure 7).

Patient was discharged then followed up for a period of 15 months with no sign of recurrence (Figures 8 and 9).

\section{Discussion}

Some surgeons reported keratocystic odontogenic tumor invading or associated with maxillary sinus related to impacted third molar in rare cases (less than 1\%), it may also exhibits displacement to adjacent structures (Brannon RB. 1976). Two cases were reported in which KCOT was found in maxillary sinus associated with maxillary third molar impacted in the sinus completely. However maxillary alveolar bone was intact and not related to the lesion. These two cases were managed with enucleation $\&$ curettage, they did not show any recurrence in five to eight years follow up [9]. Similar cases were reported where third molar was impacted in the sinus destroying \& displacing its roof \& lateral wall, the lesions were either excised and curetted or enucleated \& treated with carnoy's solution. No recurrence

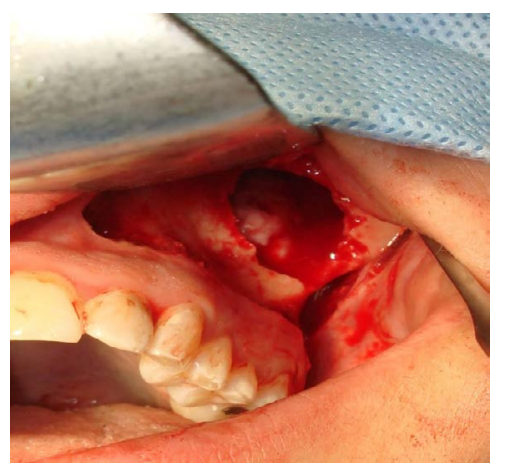

Figure 5. KCOT within left maxillary sinus is exposed through Caldwell Luc approach.

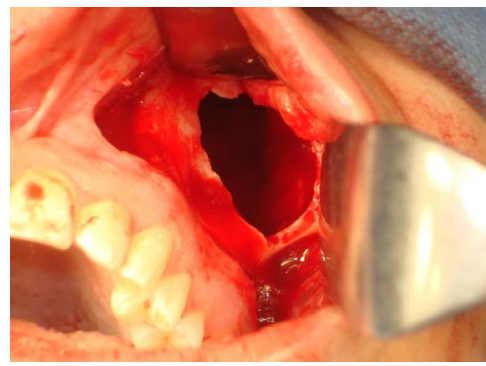

Figure 6. Post-enculation area of the lesion.

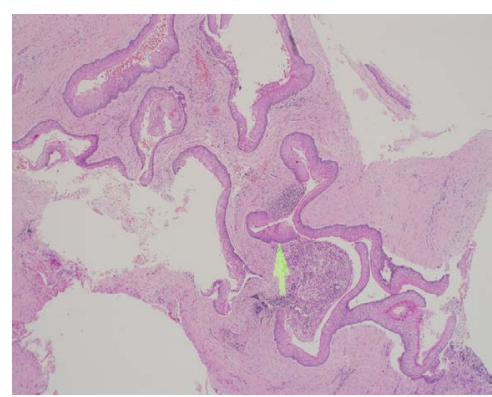

Figure 7. Prominent multilocularity \& and undulating type (arrow) Keratocyst epithelial lining. $\mathrm{H} \& \mathrm{E} ; 40 \mathrm{x}$.

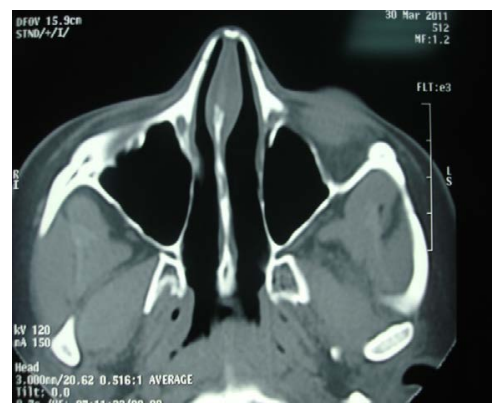

Figure 8. Axial C.T Scan 10 months post-operatively with no sign of KCOT recurrence.

was reported up to the follow up date [10,11].

This particular case is presenting an unusual picture of KCOT where it was found in maxillary sinus with no relation to either ectopically erupted or impacted teeth.

Clinically, in most patients, pain, swelling or both, are shown, but there are also cases with no symptoms [4]. Patients with multiple KCOTs, with or without nevoid basal cell carcinoma syndrome (NBCCS), are generally younger than those with single KCOT [5]. 


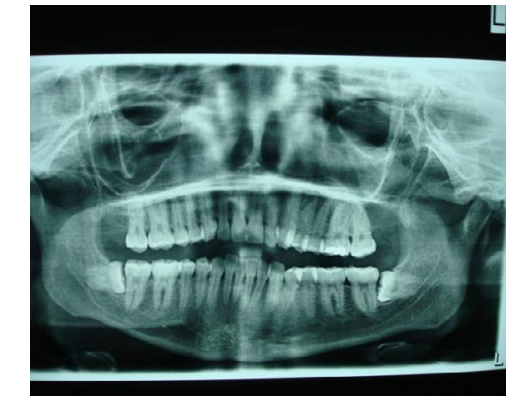

Figure 9. OPG radiograph 15 months post-operatively.

(Neville BW et al 2002) [12] reported that in $25 \%$ - $40 \%$ of cases the lesion was involved with an unerupted tooth.

In recent studies a somatic mutation of PTCH gene in some odontogenic keratocysts have been implicated [13]

Histologically, they are characterized by the presence of a thin bandlike parakeratinized or orthokeratinized stratified squamous epithelium, with a prominent basal layer composed of either columnar or cuboidal cells, and connective tissue wall that is usually free of inflammation. Depending on the characteristics of the lining and the type of keratin produced, they are classified into 2 subtypes: parakeratotic and orthokeratotic. Parakeratotic KCOTs recur far more than orthokeratotic KCOTs [14].

KCOTs grow by the extension of fingerlike processes into marrow spaces rather than by expansion, and the tumor wall grows greater than the tumor cavity expands, so the wall lining becomes folded.

The KCOT frequently perforates adjacent cortical bone and may lie partially within soft tissue [15].

There are two methods of treatment, conservative and aggressive. In the conservative method, simple enucleation with or without curettage and marsupialization is suggested. Aggressive methods include peripheral ostectomy, chemical curettage with Carnoy's solution, and resection $[4,5]$.

Reported recurrence rates for KCOTs range from $5 \%$ to about $70 \%$ [3].

\section{Conclusion}

Keratocystic odonntogenic tumor may arise within the maxillary sinus with or even without an impacted tooth. Considering this fact during management of the patient may significantly affect types of management chosen and the tumor recurrence rate.

\section{Acknowledgment}

I would like to express my deepest thanks and appreciation to the following people for their help in preparing this paper:

- Dr. Yousef Al-Marzooq.

- Dr. Khasim Al-Alwan.

- Mr. Anwar Al-Bagshi.

- Ms. Fatima Al-Mearaj

\section{References}

1. Barnes L, Eveson JW, Reichart P and Sidransky D (2005). Pathology and genetics of head and neck tumours. Lyon: IARC Press

2. Marx RE, Stern D (2002) Oral and maxillofacial pathology: a rationale for diagnosis and treatment. Chicago, IL: Quintessence Publishing.

3. Ali M, Baughman RA (2003) Maxillary odontogenic keratocyst: a common and serious clinical misdiagnosis. J Am Dent Assoc 134: 877-883. [Crossref]

4. Morgan TA, Burton CC, Qian F (2005) A retrospective review of treatment of the odontogenic keratocyst. J Oral Maxillofac Surg 63: 635-639. [Crossref]

5. Gold L, Upton GW, Marx RE (1991) Standardized surgical terminology for the excision of lesions in bone: an argument for accuracy in reporting. J Oral Maxillofac Surg 49: 1214-1217. [Crossref]

6. Chen CH, Lin CC (1986) Clinical and histopathological study of the odontogenic keratocyst--a follow-up study of 16 cases. Gaoxiong Yi Xue Ke Xue Za Zhi 2: 601-607. [Crossref]

7. Precheur HV, Krolls SO (2009) An unusual presentation of an odontogenic keratocys in the buccal space: case report. J Oral Maxillofac Surg 67: 2513-2515. [Crossref]

8. Yonetsu K, Bianchi JG, Troulis MJ, Hugh D (2001) Curtin AJNR Am J Neuroradiol 22:1887889

9. Silva GCC, Silva EC, Gomez RS, Vieira TC (2006) Odontogenic keratocyst in the maxillary sinus: Report of two cases, Oral Oncology EXTRA 42, 231-234.

10. Çakur B, Miloglu O, Yolcu U, Göregen M, Gürsan N (2008) Keratocystic odontogenic tumor invading the right maxillary sinus: a case report, J Oral Sci 50: 345-349.

11. Ortakoúlu K, Süer BT, Ençümen M (2005) A Large Odontogenic Keratocyst Containing A Third Molar Tooth in The Maxillary Antrum, Turk J Med Sci 35: 341-346

12. Neville BW, Damm DD, Allen CM, Bouguot JE (2002) Oral and maxillofacial pathology. 2nd ed, Saunders, Philadelphia 595.

13. Barreto DC, Gomez RS, Bale AE, Boson WL, De Marco L (2000) PTCH gene mutations in odontogenic keratocysts. J Dent Res 79: 1418-1422. [Crossref]

14. Brannon RB (1976) The odontogenic keratocyst. A clinicopathologic study of 312 cases. Part I. Clinical features. Oral Surg Oral Med Oral Pathol 42: 54-72. [Crossref]

15. Cawson RA, Odell EW (1998) Essentials of oral pathology and oral medicine. 3rd ed. London: Churchill Livingstone.

Copyright: (C2016 Al-Bodbaij MH. This is an open-access article distributed under the terms of the Creative Commons Attribution License, which permits unrestricted use, distribution, and reproduction in any medium, provided the original author and source are credited. 